\title{
Trivial Trauma Induced Bilateral Proximal End Humerus fracture: Two case reports
}

Hasan Kara, Aysegul Bayir, Ahmet Ak, Demet Acar, Murat Akinci, Selim Degirmenci From the Selcuk University, Faculty of Medicine, Department of Emergency Medicine, Konya, Turkey.

\section{Abstract:}

Humerus proximal end fractures constitute $45 \%$ of the humerus fractures. Humerus proximal end fractures are encountered at the rates of $4-5 \%$ in the extremity fractures. This rate increases to $76 \%$ in the cases over 40 years old. Twenty percent of these fractures are displaced fractures and they require surgical intervention. Causes of bilateral humerus proximal end fractures include convulsions caused by electric shock, epilepsy, alcohol deprivation and hypoglycemia that commonly cause sudden and hyper-muscle contractions. While bilateral humerus proximal end fractures are usually accompanied by shoulder dislocations, our cases resulted from simple falls caused by high energy traumas without being unconscious. In this study, two cases, which developed bilateral humerus proximal end fractures as a result of simple fall, were examined in the light of literature.

Key words: Humeral Fractures, Shoulder fractures, Shoulder Dislocation, Seizures, Epilepsy.

Introduction

Humerus proximal fractures constitute about $5 \%$ of the extremity fractures. While humerus proximal end fractures in young patients are caused by high energetic traumas such as traffic accidents, falling down from height and being shot, lower energetic traumas like falling down while walking in the house can cause fractures in the osteoporotic cases. Fractures occur three times more in females than males in parallel with osteoporosis increase. Fractures can result from the trauma straight on the shoulder or from the load pressure onto the arm while falling down, and sometimes pathologic fractures may occur. Humerus proximal end fractures can occur either as isolated cases or as a part of a multiple trauma. Although determinant diagnosis can be established through radiology, complete anamnesis and physical examination are also essential. The outlook of shoulder and neurovascular changes should be evaluated attentively. In this study, two cases developing bilateral humerus proximal end fractures as a result of simple fall were examined in the light of literature.

\section{Case Reports}

\section{Case 1}

A 62-year-old female patient applied to the

Corresponding Author: Dr. Hasan Kara

Email: hasankara42@gmail.com

Received: August 29, 2013 | Accepted: September 23, 2013 | Published Online: October 20, 2013 This is an Open Access article distributed under the terms of the Creative Commons Attribution License (creativecommons.org/licenses/by/3.0)

Conflict of interest: None declared | Source of funding: Nil | DOl: http://dx.doi.org/10.17659/01.2013.0085 
emergency service with the complaints of pain, movement restriction, swelling in both arms and sensitiveness in the neck as a result of falling in the bathroom. She was conscious, oriented and cooperative. Her blood pressure was 132/88 $\mathrm{mmHg}$, pulse was $78 / \mathrm{min}$, and her neurologic examination was normal. She had right humerus Neer type- 4 proximal fracture and left humerus proximal fracture in the X-ray and Computed Tomography (CT) images [Fig.1-2]. After the consultation with the orthopedic clinic, the patient was hospitalized to have an operation in the orthopedic clinic with the diagnosis of bilateral humerus proximal end fracture.

\section{Case 2}

A 72-year-old female patient applied to the emergency service with the complaints of pain and movement restriction in both shoulders as a result of falling off a ladder. She was conscious, oriented and cooperative. Her blood pressure was 120/83 $\mathrm{mmHg}$, pulse was $73 / \mathrm{min}$, and her neurologic examination was normal. There was right humerus Neer type- 3 humerus proximal fracture and left

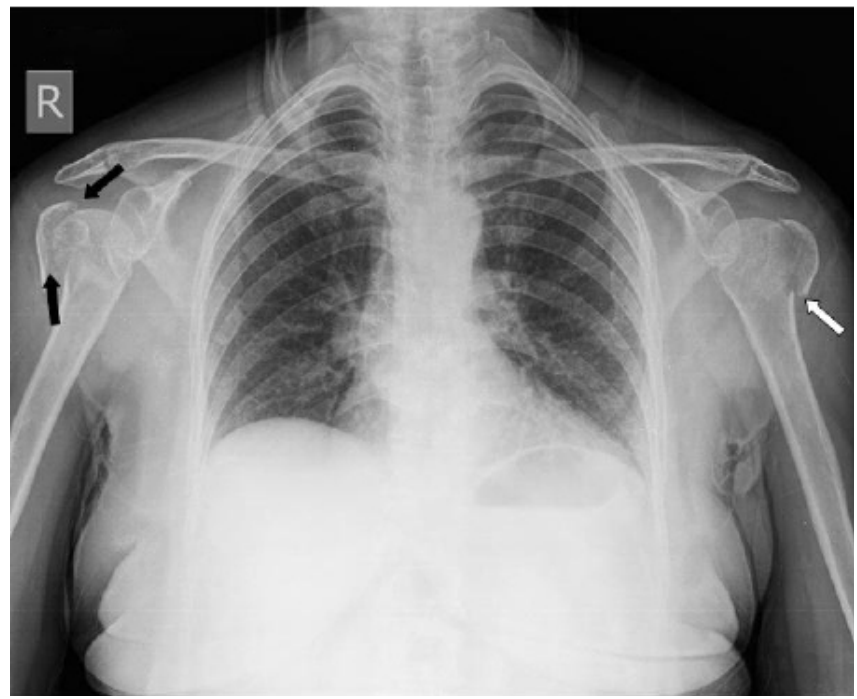

humerus tuberculum majus fracture in the $\mathrm{X}$-ray and CT images [Fig.3-4]. The patient was hospitalized to have an operation in the orthopedic clinic with the diagnosis of bilateral humerus proximal end fracture after the consultation with the orthopedic clinic.

\section{Discussion}

It has been observed that as the average life expectancy has increased, shoulder fractures as in the hip fractures are encountered more often especially in the osteoporotic people. Humerus proximal end fractures constitute $45 \%$ of all humerus fractures. Humerus proximal end fractures are encountered at the rates of $4-5 \%$ in the extremity fractures. This rate increases to $76 \%$ in the cases over 40 years old [1]. Twenty percent of these fractures are displaced fractures and they require surgical intervention. Comminuted fractures around the neck have been seen more often as the life expectancy has increased, and the aged population with osteoporotic bones expose to traumas more. Comminuted fractures in the osteoporotic elderly people are caused by even with simple traumas followed by domestic accidents.

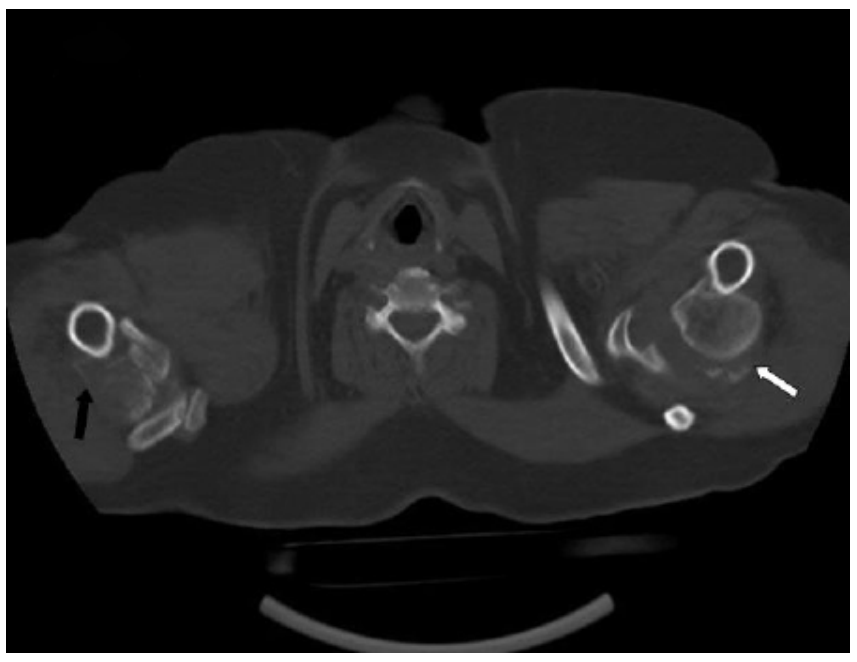

Fig.1-2: Black arrows: Right humerus Neer type-4 humerus proximal fracture; White arrows: left humerus proximal fractured dislocation. 

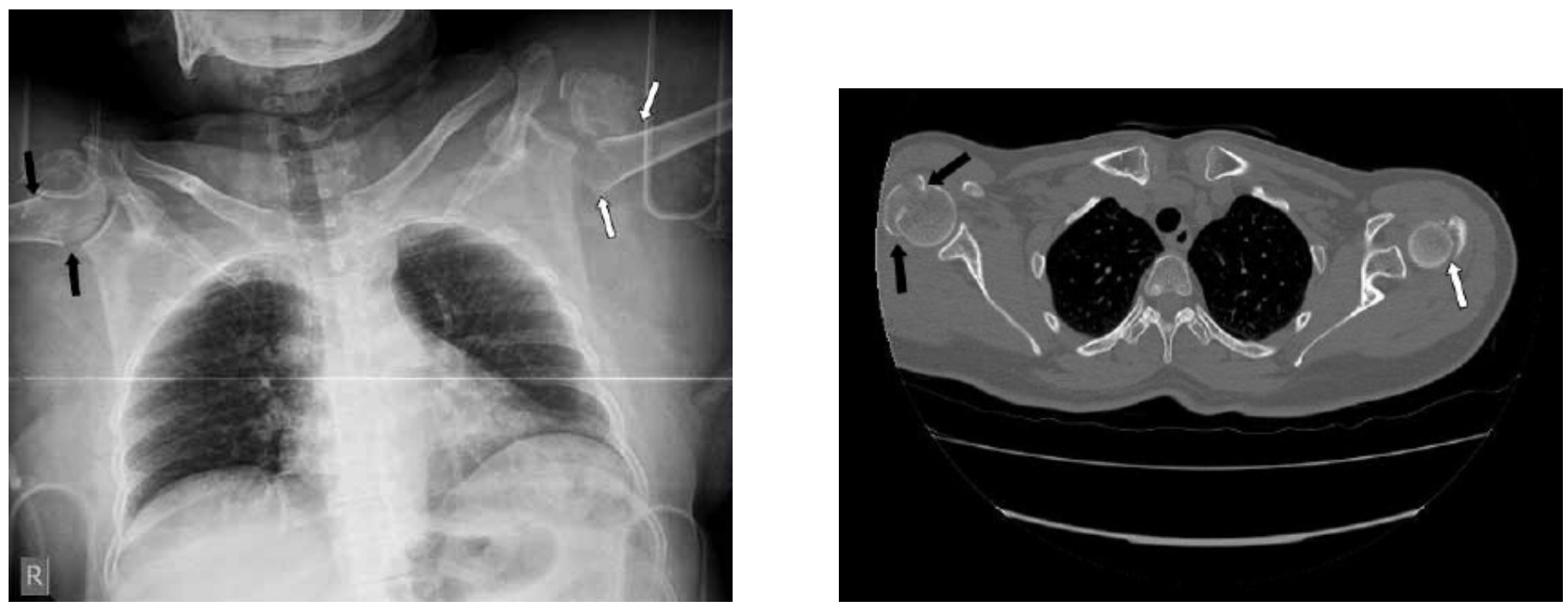

Fig.3-4: Black arrows: Right humerus Neer type-3 humerus proximal fracture; White arrows: left humerus tuberculum majus fracture.

Since the bone density decreases in osteoporotic cases, the metaphyseal region of proximal humerus becomes more susceptible to fractures. Generally, they occur more frequently in the cases over 60 years old. They occur three times more in females than males [2]. Both of our cases were women who were 60 years old and fracture resulted as a result of simple trauma. Since the proximal humerus region is in metaphyseal bone structure, it can be broken easily even with simple traumas [3]. The common features of both cases were that they both did not have hypoglycemia, cerebrovascular event, epilepsy, and were not exposed to electric current in the etiology of their fall, and both of them were female and elderly. Other fractures and diseases may accompany as the quality of the elderly people bones is generally poor. Movements of the shoulder joint are achieved with the help of the muscle mass surrounding humerus. The more damaged the surrounding soft tissues, the more internal fixation and early functional treatment is needed [4].

Industrial machines and firearms and chiefly the use of motor vehicles have been increasing rapidly in parallel with the advancement in technology in the world. Correspondingly, the rate of occurring humerus shaft fracture has been increasing. The mechanism of injury is produced by indirect mechanism; falling directly on top of the shoulder while the shoulder is in adduction state or falling onto the open hand while the arm is in abduction position [5]. Most of the humerus proximal end fractures are non-displaced or minimal displaced. Sometimes humeral head dislocations may accompany them [6]. These fractures and dislocations are generally treated with conservative treatment methods, and occasionally some cases can be treated with surgical approaches. Humerus shaft fractures are often caused by high energy traumas. Besides the location and type of the fracture, their anatomic closeness to the neurovascular structures makes them more important [7]. The reasons for the rarely seen bilateral humerus proximal end fractures are generally the convulsions which cause sudden and extreme muscle spasm caused by epilepsy, electric shock, alcohol deprivation and hypoglycemia. The suggested mechanisms of the shoulder injury that occurs during convulsive seizure are the typical position of the shoulder, adduction, internal rotation and flexion. Humeral head is forced superior 
and posterior on the glenoid cavity with spasms. Moreover, convulsive force ends up with a complex proximal humerus fracture when humeral head hits glenoidal rim [8]. Because nearly $50 \%$ of the cases, who wake up with shoulder pain without any trauma history and live the first episode of convulsive seizure, cannot describe their complaints properly at their first application, establishing that diagnosis of these types of traumas are delayed. At least one antero-posterior and one axillary graph are required along with taking right history and physical examination while assessing a patient with the complaints of shoulder. At physical examination, shoulder contour may seem normal due to processus coracoideus pressure. The painful abnormal action in the fractured area can be misperceived for the normal glenohumeral movement. One should be careful against nerve injuries. CT makes it possible to establish the lesion completely and it is essential for surgical planning. While bilateral humerus proximal end fractures are accompanied by shoulder dislocations in such traumas in the literature, our cases occurred with simple falls caused by low energetic trauma without being unconscious. We held a consultation with the orthopedic clinic for both cases, and fracture was reduced by giving them Tramadol, a synthetic opioid. The cases were transferred with their long arm plastered bilaterally to this clinic so that an operation could be performed there.

\section{Conclusion}

Humerus proximal fractures can be caused by even a simple trauma in the osteoporotic elderly patients admitted to emergency services for shoulder pain complaints, so at least one antero-posterior and one axillary graph should be taken along with taking right history and physical examination.

\section{References}

1. Hartsock LA, Estes WJ, Murray CA, Friedman RJ. Shoulder hemiarthroplasty for proximal humeral fractures. Orthop Clin North Am. 1998;29:467475.

2. Smith WR, Kınık H. Kas-iskelet sistemi travma cerrahisi. In: Skinner HB, Alpaslan $M$, editors. Current ortopedi güncel tanı ve tedavi. 3rd ed. Ankara Güneș Kitabevi; Lange Medical books; 2005:112-118.

3. Elena-Sorando E, Agulló-Domingo A, JuanGarcia E, Amrouni B. Bilateral shoulder fractures secondary to accidental elektrical injury. Ann Burns Fire Disasters. 2006; 19:41-43.

4. Fenichel I, Oran A, Burstein G, Perry M. Percutaneous pinning using threaded pins as a treatment option for unstable two- and threepart fractures of the proximal humerus: a retrospective study. Int Orthop. 2006;30:153157.

5. Gorschewsky O, Peutz A, Klakow A, Pitzl $M$, Neumann $W$. The treatment of proximal humeral fractures with intramedullary titanium helix wire by 97 patients. Arch Orthop Trauma Surg. 2005; 1 25:670-675.

6. Szyszkowitz R, Akalın S. Humerus üst uç. In: Rüedi TP, Murphy WM, Ağuș $H$, editors. Kırık tedavisinde AO kuralları. Davos: AO Yayınları 2000:271-289.

7. Aydın A, Aköz A, Bayramoğlu A, Uzkeser $M$, Șahin $H$, Çakır ZG. Shoulder dislocation and non displaced humerus head fracture due to epileptic attack. Akademik Acil Tıp Olgu Sunumları Dergisi. 201 2;3:30-32.

8. Paavolainen $P, B j o ̈ r k e n h e i m ~ J M$, Slätis $P$, Paukku P. Operative treatment of severe proximal humeral fractures. Acta Orthop Scand. 1983;54:374-379. 